\begin{tabular}{c|c|c}
\hline \hline $\begin{array}{c}\text { Vol. 393: 131-146, 2009 } \\
\text { doi: } 10.3354 / \text { meps08241 }\end{array}$ & $\begin{array}{c}\text { MARINE ECOLOGY PROGRESS SERIES } \\
\text { Mar Ecol Prog Ser }\end{array}$ & Published October 30 \\
\hline \hline
\end{tabular}

\title{
Degraded recruitment synchrony in Northwest Atlantic cod stocks
}

\author{
Jennifer E. Kelly ${ }^{1, *}$, Kenneth T. Frank ${ }^{2}$, William C. Leggett ${ }^{3}$ \\ ${ }^{1}$ Department of Oceanography, Dalhousie University, 1355 Oxford Street, Halifax, Nova Scotia B3H 4J1, Canada \\ ${ }^{2}$ Department of Fisheries and Oceans, Bedford Institute of Oceanography, Ocean Sciences Division, PO Box 1006, Dartmouth, \\ Nova Scotia B2Y 4A2, Canada \\ ${ }^{3}$ Department of Biology, Queen's University, Kingston, Ontario K7L 3N6, Canada
}

\begin{abstract}
Correlated recruitment between North Atlantic cod stocks, separated by hundreds of kilometers, has consistently been interpreted as indicative that a proportion of pre-recruit mortality is forced by large-scaled abiotic conditions. This large-scale pattern was based on analyses that predated the overexploitation-driven stock abundance declines and collapses of the 1990s. We used a sliding window analysis to examine the temporal trajectories of the e-folding decorrelation scales of synchrony of both bottom temperature and de-trended cod recruitment for the Northwest Atlantic from 1950 to 2006. The characteristic scale of temperature synchrony rose from roughly $400 \mathrm{~km}$ to $800 \mathrm{~km}$ in the 1990s. Rather than mirror changes in temperature as expected, the scale of cod recruitment synchrony declined in the 1990s from roughly $500 \mathrm{~km}$ to $250 \mathrm{~km}$, coincident with the severe declines in abundance. Dispersal between populations, another mechanism that generates synchronous population dynamics, may have been an overlooked contributor to recruitment synchrony documented in earlier analyses. Cod are highly mobile, and it has been suggested that they are structured as metapopulations. Over-exploitation may have interrupted these dispersal patterns and the associated metapopulation structure, thereby reducing synchrony. If so, dispersal from the most productive of the remaining populations may be an avenue for future recovery.
\end{abstract}

KEY WORDS: Recruitment synchrony · Decorrelation · Dispersal · Atlantic cod · Population dynamics $\cdot$ Temperature $\cdot$ Depensation

Resale or republication not permitted without written consent of the publisher

\section{INTRODUCTION}

Spatially distant populations of a single species often fluctuate in synchrony (Liebhold et al. 2004). In fishes, for example, synchronous population dynamics have been described for numerous individual species (e.g. sockeye salmon, Peterman et al. 1998; pink salmon, Pyper et al. 2001; rockfish, Field \& Ralston 2005; winter flounder, Manderson 2006), and meta-analysis of many temperate stock recruitment time series have demonstrated that synchrony occurs commonly in marine and anadromous fishes (Myers et al. 1997).

In general, the strength of synchrony declines with the geographic distance between populations, although more complex spatial patterns have also been observed (Bjørnstad et al. 1999). Three primary mechanisms lead to synchrony of population dynamics: (1) populations are similarly forced by synchronous exogenous environmental conditions (e.g. climate, primary productivity levels), (2) predator-prey, parasitehost, or other community-level trophic interactions with differentially mobile species force population abundances into synchrony, and/or (3) dispersal of individuals between populations synchronizes abundances (Bjørnstad et al. 1999, Liebhold et al. 2004). Synchrony, when determined by the first 2 mechanisms, reflects a degree of vulnerability; homogeneous dependence upon a particular forcing leaves all affected populations prone to simultaneous crashes following a stochastic disaster and to simultaneous out- 
bursts during favorable conditions. Synchrony resulting from dispersal must be interpreted contextually. Where dispersal between populations is a regular characteristic of the species, as in the case of those species that form metapopulations, some synchrony is indicative of a functioning system. Alternatively, metapopulation persistence is enhanced when the dynamics of local populations fluctuate sufficiently independently to ensure that some recolonizers will survive stochastic disasters (Hanski \& Gilpin 1997).

Northwest Atlantic cod Gadus morhua stocks have been repeatedly shown to exhibit synchronous recruitment dynamics, and the correlated recruitment between stocks separated by hundreds of kilometers has been interpreted as evidence of recruitment forcing by large-scale environmental conditions. Early qualitative analyses demonstrated that many adjacent and disjunct cod stocks throughout the North Atlantic produced very strong year-classes simultaneously or at a 1 yr lag (Templeman 1972). Principal components analyses and correlation analyses provided further support for pan-oceanic (Garrod \& Colebrook 1978) and pan-Northwest Atlantic (Koslow 1984) recruitment synchrony. While these scales suggested that abiotic environmental forcing in part determines pre-recruit cod mortality, the poorly-understood mechanisms by which the largest-scale abiotic conditions, in confluence with more localized conditions, force recruitment synchrony in cod were judged likely to be irresolvable (Koslow et al. 1987). Step-wise multiple regression analyses of sea surface temperature, the dominant wind field, air pressure, and freshwater river discharge, for example, failed to identify a primary correlate of cod recruitment. Correlation analysis has proven a limited tool in environment-recruitment studies. Identified correlations are often short-lived, and are potentially spurious, as most environmental variables are intercorrelated. Correlation analyses are also incapable of identifying non-linear relationships (Koslow et al. 1987, Myers 1998). Recent work has demonstrated that the effects of climate (the North Atlantic Oscillation, NAO) on cod recruitment are nonstationary (Stige et al. 2006), which may in part explain the failures of past time series analyses to identify persistent linkages.

The autocorrelation inherent in recruitment time series further complicates analyses of synchrony (Thompson \& Page 1989). Similar strong recruitment trends could swamp yearly variability of a much smaller magnitude. Some long-term recruitment trends are undoubtedly genuinely induced by ecological factors operating on long time scales, but these are inseparable from spurious trends introduced by abundance estimation methods (Thompson \& Page 1989, Myers et al. 1995). Fishing-driven trends in cod stock biomasses also have the potential to generate synchronous recruitment trends. However, Thompson \& Page (1989) found that Northwest Atlantic cod recruitment synchrony persisted after the recruitment time series were high-pass filtered by first-differencing. They attributed about $40 \%$ of the recruitment variability to large-scale forcing, resulting in synchrony, and the remainder to local factors. Statistical analysis provided no evidence to suggest that closer stocks were more strongly correlated than distant stocks.

Myers et al. (1995) applied decorrelation analysis in their attempt to describe the spatial component of Atlantic cod recruitment synchrony. Though less powerful statistically, this methodology generated an intuitive characteristic length scale. Recruitment time series were de-trended in 2 steps: (1) conversion into residuals from a stock-recruitment model to account for trends in spawning stock biomass (SSB), and (2) conversion into residuals from Lowess smoother fits (10 yr window) of the SSB-corrected recruitment time series. The coefficients of pairwise correlations between all stocks were then plotted against the distance separating the stock spawning grounds. The fitted exponential declines of synchrony over distance were characterized by e-folding decorrelation scales (the distance at which correlation falls to $\mathrm{e}^{-1}$ ) of $400 \mathrm{~km}$ for all North Atlantic stocks, $460 \mathrm{~km}$ for Northwest Atlantic stocks, and $340 \mathrm{~km}$ for northeast Atlantic stocks. These scales are in keeping with the classic interpretation that large-scale abiotic variables force synchronous recruitment variability in cod.

As reflected above, environmental forcing has been the dominant focus of studies of population synchrony in Northwest Atlantic cod. Dispersal, on the other hand, while potentially important as a generator of synchrony, has been largely overlooked. Stray rates from tagging studies indicate a moderate to high level of exchange between cod populations and stock mixing during the non-breeding season (Robichaud \& Rose 2004). A metapopulation structure, which by definition involves dispersal, has been explicitly hypothesized for the northern cod complex on the Labrador and Newfoundland continental shelves (Smedbol \& Wroblewski 2002), and for the West Scotland and North Sea stocks in the northeastern Atlantic (Wright et al. 2006). Indeed, while the cod stocks of the Northwest Atlantic are generally managed as single units, a substantial body of meristic (Templeman 1962), genetic (Ruzzante et al. 1999, Pogson et al. 2001, Wirgin et al. 2007), and behavioral (Robichaud \& Rose 2004) data suggests that these stocks have spatial (bank, bay), temporal (timing of spawning), and depth-dependent substructuring (Swain \& Frank 2000) that are similar in character to the substructuring of metapopulations. 
The data that have been amassed since the last comprehensive analysis of recruitment synchrony in Northwest Atlantic cod (Myers et al. 1995) now allow for an investigation of cod recruitment synchrony not only in the spatial but also in the temporal domain. In this paper we examine the temporal evolution of both the spatial synchrony of cod recruitment and the spatial synchrony of one large-scale abiotic environmental measure: bottom temperature. The conclusions of previous work set the expectation that the temporal evolution of the scale of cod recruitment synchrony would mirror that of the environment, the proposed forcing factor. Temperature is one component of the climate that certainly influences the life histories of marine fish (e.g. Brander 1995, 2000, Mueter et al. 2002). In the northernmost stocks, recruitment directly correlates with water temperature, although this relationship becomes indiscernible in more temperate populations (Planque \& Fredou 1999). The spatial pattern of the effects of climate (the NAO index) on sea surface temperature strongly resembles that of the effects of climate on cod recruitment throughout the North Atlantic (Stige et al. 2006).

Recent temporal changes in the biomass of the Northwest Atlantic cod stocks have been dramatic. In the 1990s, all 12 managed stocks suffered severe declines, the most extreme and well-known example being the collapse of the northern cod stock (Northwest Atlantic Fisheries Organization [NAFO] Division $2 \mathrm{~J} 3 \mathrm{KL}$ ) to $1 \%$ of its historical maximum biomass (Marteinsdottir et al. 2005). Only 5 of the stocks have shown signs of recovery, and in only one of these has the recovery been significant (Shelton et al. 2006). These sustained low abundances have potential implications both for individual stock dynamics and for inter-stock connectivity, and thus may be reflected in an updated analysis of recruitment synchrony.

\section{MATERIALS AND METHODS}

Abiotic environment. The shelf bottom temperature anomalies we analyzed are derived from hydrographic data collected during annual Department of Fisheries and Oceans, Canada (DFO), and National Marine Fisheries Service, United States (NMFS), government research vessel groundfish surveys. These bottom temperature data are aggregated by NAFO stock division groupings, and, with the exception of the Flemish Cap and the northern Gulf of St. Lawrence for which data were not available, cover the range of the cod stocks considered here (Fig. 1): (A,B) Labrador, (C) Grand Banks, (D) southern Newfoundland, (E) southern Gulf of St. Lawrence, $(F)$ Sydney Bight, $(G, H)$ eastern Scotian Shelf, (I) western Scotian Shelf, (J) Georges Bank,

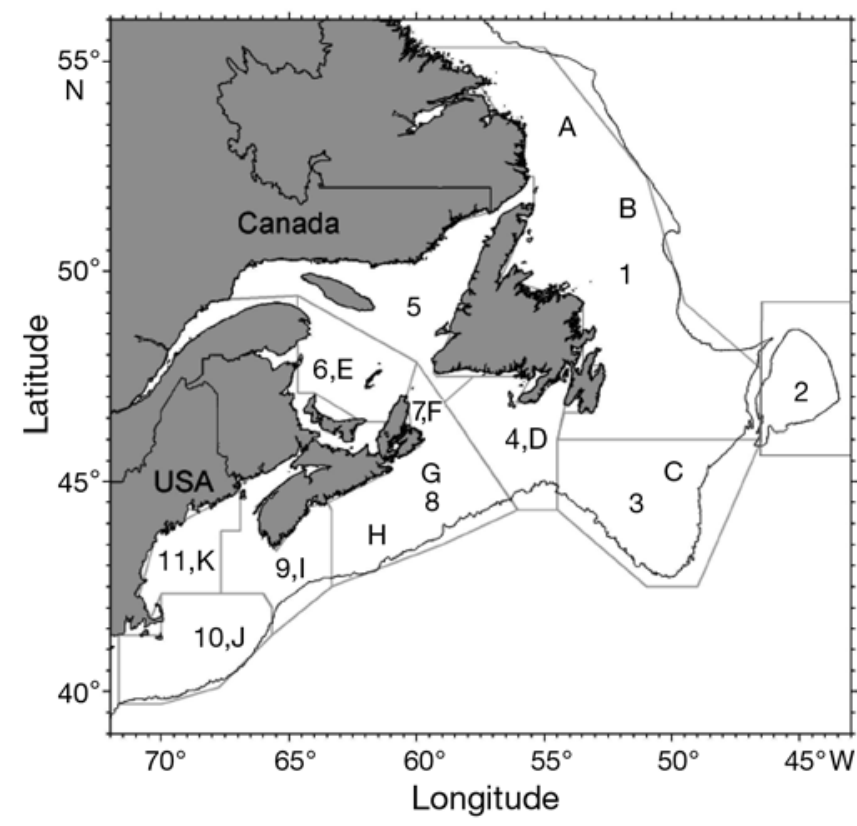

Fig. 1. Gadus morhua. Locations (latitude and longitude) assigned to Northwest Atlantic cod stock spawning grounds (1-11) and to bottom temperature anomaly time series (A-K). Coordinates are listed in Table 1. Grey lines delineate the NAFO convention areas associated with each stock. (1) Southern Labrador, northern Grand Banks, (2) Flemish Cap, (3) southern Grand Banks, (4) St. Pierre Bank, (5) northern Gulf of St. Lawrence, (6) southern Gulf of St. Lawrence, (7) Sydney Bight, (8) eastern Scotian Shelf, (9) western Scotian Shelf, Bay of Fundy, (10) Georges Bank, (11) Gulf of Maine

(K) Gulf of Maine (A-D: Colbourne et al. 2006, E. Colbourne pers. comm.; E: B. Petrie pers. comm.; F-I: Petrie et al. 2006; J-K: Link \& Brodziak 2002). Details and geographic coordinates are listed in Table 1, and the time series are plotted as standardized anomalies in Fig. 2. For location J, a missing year of data was assigned a value of 0 , the average anomaly, for the analyses.

Cod recruitment. Eleven of the 12 managed Northwest Atlantic cod stocks were analyzed for synchrony in recruitment (Fig. 1): (1) southern Labrador, northern Grand Banks, (2) Flemish Cap, (3) southern Grand Banks, (4) southern Newfoundland, (5) northern Gulf of St. Lawrence, (6) southern Gulf of St. Lawrence, (7) Sydney Bight, (8) eastern Scotian Shelf, (9) western Scotian Shelf, Bay of Fundy, (10) Georges Bank, (11) Gulf of Maine. The Northern Labrador stock was excluded because the time series for that stock are incomplete. Time series of number of Age 1 recruits and SSB were obtained from the compilation of NAFO, DFO, and NMFS stock assessments contained in Shelton et al. (2006). These data series were derived from age-structured population models of catch-at-age and survey data, the sole exception being the data series 
Table 1. Gadus morhua. (a) Stock name, stock number, NAFO division (stock label used by management), first and last year classes in the recruitment time series, first and last years of spawning stock biomass (SSB) time series, and location assigned as the spawning ground for distance computations for the 11 Northwest Atlantic cod stocks used in the analysis. (b) Associated bottom temperature measurements relevant to each stock, first and last years in the temperature time series, missing values, time of year of measurements, and location assigned for distance computations

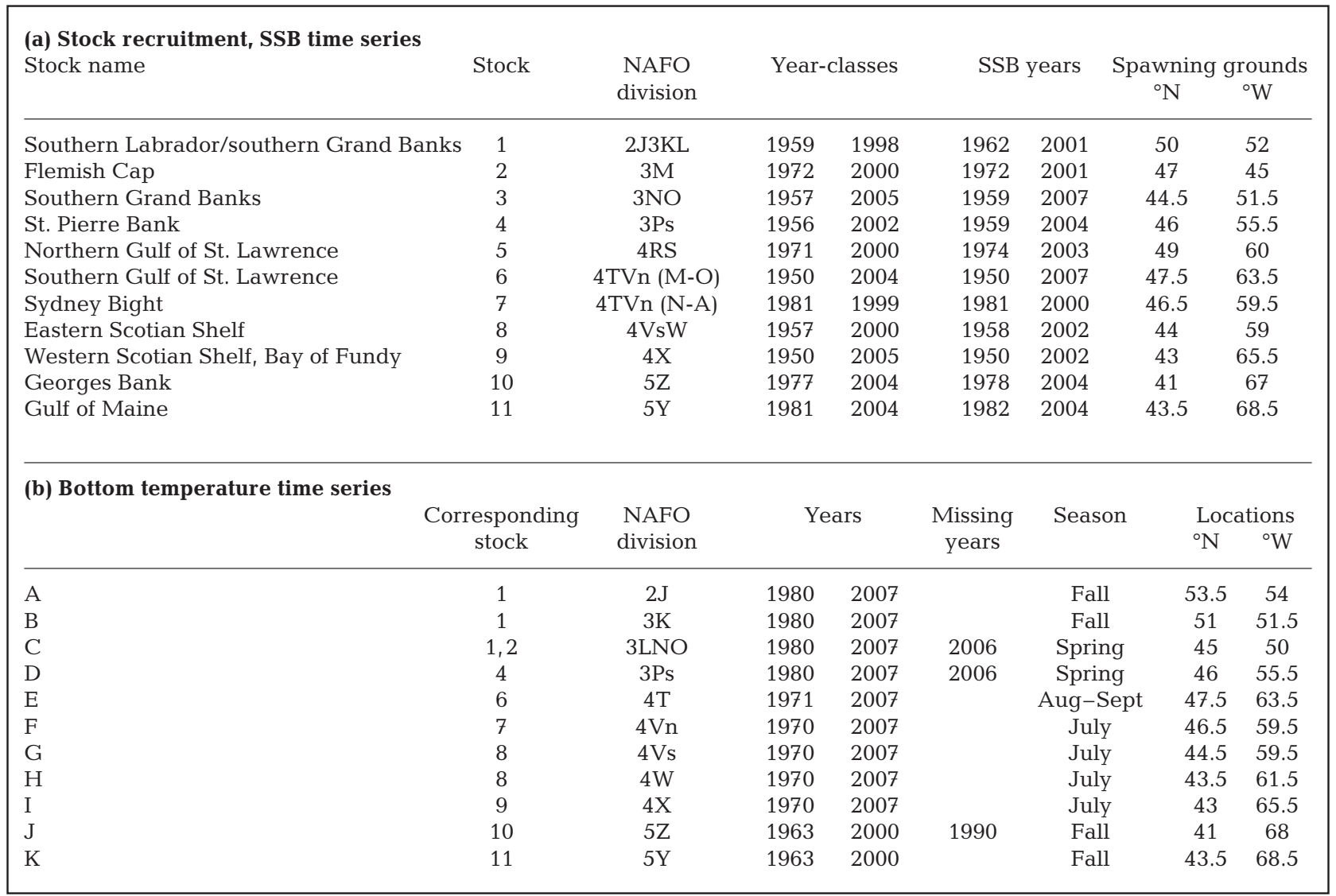

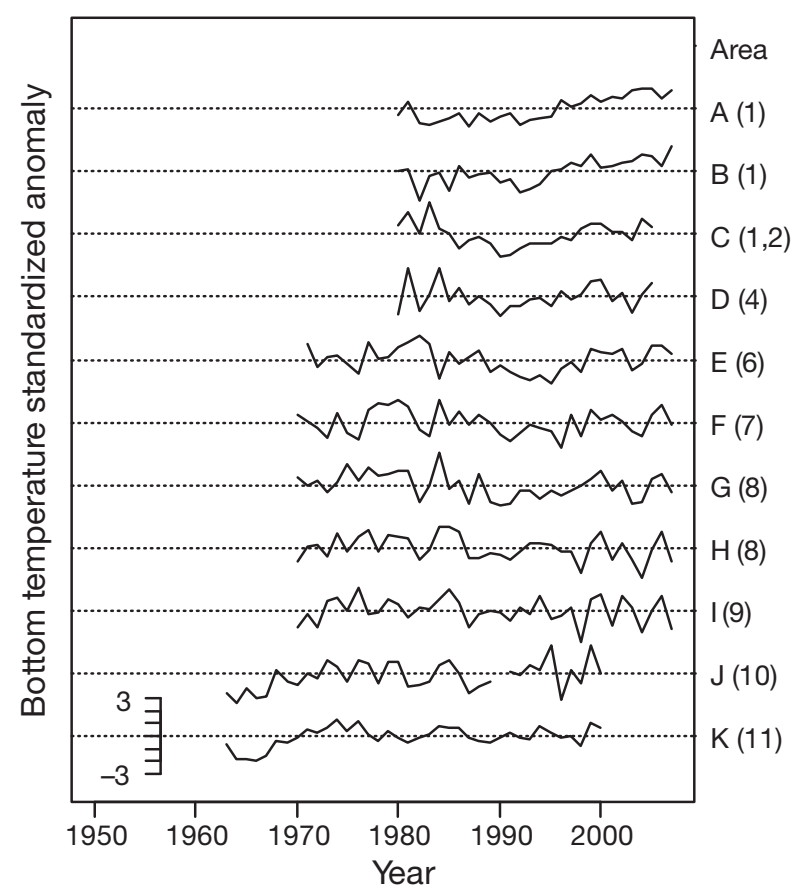

for Stock 8, to which a research vessel survey-based recruitment index applies (Shelton et al. 2006).

Recruitment estimates were updated with data from recently published assessments for Stocks 3 (Morgan et al. 2007), 6 (Swain et al. 2007a), 10 (O'Brien et al. 2006), and 11 (Mayo \& Col 2006). For Stocks 3 and 6, the assessment estimates of abundance at Ages 2 and 3 , respectively, were converted to Age 1 abundances using the linear fit of the Shelton Age 1 estimates versus the assessment Age 2 (Age 3) estimates for the years during which the 2 datasets overlapped. For Stocks 4, 8, 9, and 10, recruitment time series were extended to include earlier year-classes by incorporating data from the R. A. Myers Online Stock-Recruitment Database (http://ram.biology.dal. $\mathrm{ca} / \sim$ myers/data.html) The Myers data were converted to Shelton equivalents using the linear fit of the Shel-

Fig. 2. Time series of bottom temperatures as standardized anomalies (in standard deviation units) for locations throughout the range of the cod stocks (Fig. 1, Table 1), zeroed at the horizontal grid lines 
ton estimates versus the Myers estimates for the years during which the datasets overlapped. The time spans of the complete datasets are given in Table 1.

Fish recruitment generally, and Atlantic cod recruitment specifically, is grossly determined by the reproductive capacity of the spawning stock (Myers \& Barrowman 1996). We attempted to correct for the influence of trends in SSB on the recruitment time series, as did Myers et al. (1995). Estimates of SSB were obtained from the same data sources from which the estimates of recruitment were derived, and were collated using similar conversion methods. However, SSB is known to be an incomplete, and often inadequate, index of recruitment potential (Planque \& Fredou 1999, Leggett \& Frank 2008). This reality was reflected in the fact that 3 standard stock-recruitment models (linear, Ricker, and Beverton-Holt) unsatisfactorily described the data (Fig. 3). As a consequence, the time series of yearly recruitment variability derived from residuals to the stock-recruit models differed substantially depending on model choice.

We therefore chose not to attempt to isolate the influence of SSB using a theoretical stock-recruitment relationship, and instead applied a general high-pass filter to remove all long-term trends. To achieve this, the recruitment time series were $\log _{10}$ transformed and each was fit with a $10 \mathrm{yr}$ window Lowess smoother. The long-term trends described by the Lowess fit probably reflect variability in the reproductive potential of the stock, artifactual trends introduced by the agestructured population model computations, and/or trends in fisheries reporting (Myers et al. 1995), as well as long-term trends in environmental favorability. The resulting residuals to the Lowess fits were adopted as the time series of high-frequency recruitment variability.
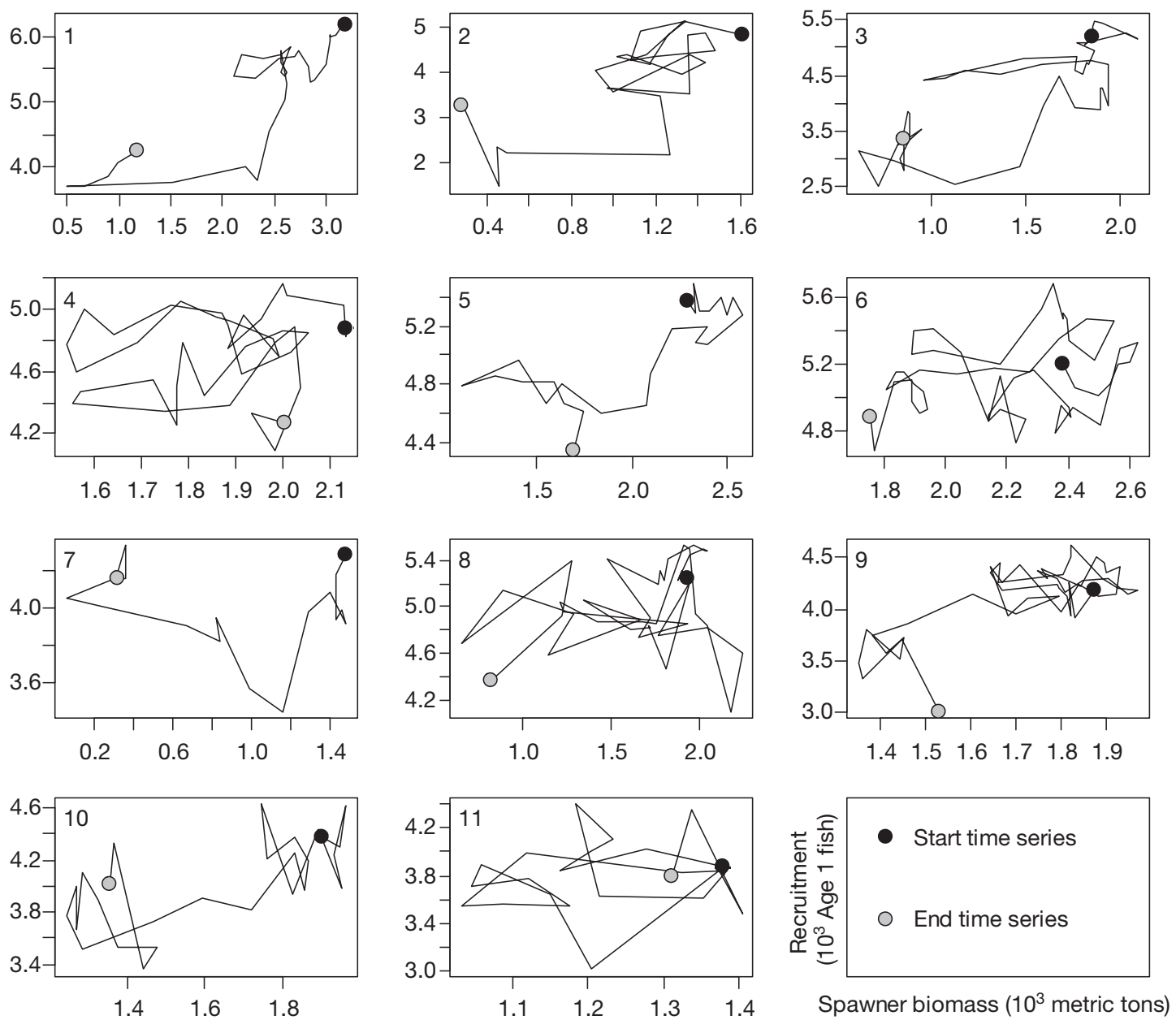

Fig. 3. Gadus morhua. Log-transformed Atlantic cod recruitment versus log-transformed spawner biomass for the 11 stocks. The temporal trajectory of the stock-recruitment relationship is traced from the earliest year in the data series (black circle) to the final year (grey circle). Strongly defined stock-recruitment relationships are generally lacking 


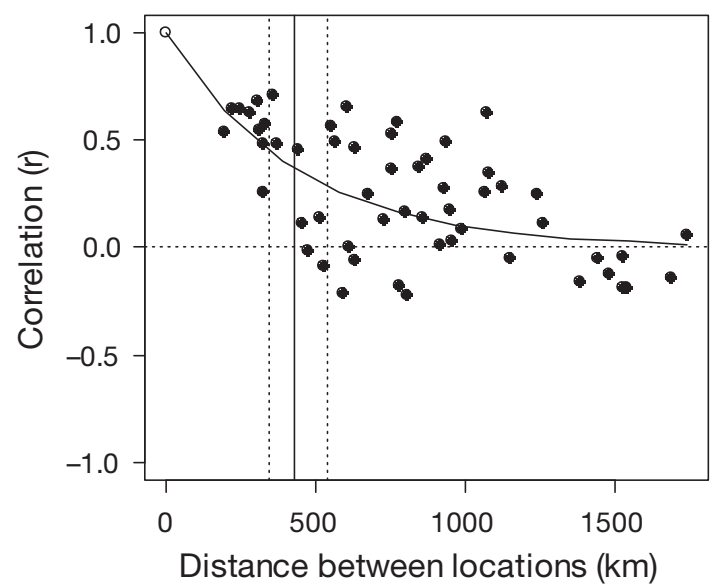

Fig. 4. Decorrelation plot of bottom temperature anomalies from 1970 to 1994, a period that includes most of the yearclasses investigated by Myers et al. (1995). For all possible location pairs, Pearson's correlation coefficient is plotted against the distance separating the 2 locations. The solid and dashed vertical lines mark the decorrelation scale and its bootstrapped confidence intervals $(5,95 \%)$ respectively. The horizontal dashed line marks zero correlation for reference

We defined the latitudes and longitudes representing the spawning grounds of individual stocks (Table 1, Fig. 1) as the approximate geographic centers of each NAFO cod management unit division. Single point geographic estimates are necessary for our analyses, whereas in reality multiple and/or diffuse spawning grounds exist within each division. The assigned locations match those used by Myers et al. (1995) as listed in the Myer's Stock-Recruitment Database. The sole exception was the Sydney Bight stock, which was not a part of the Myers et al. (1995) study.

Analytical approach. The primary method of analysis of the spatial and temporal synchrony in both the physical and biological data involved estimation of a characteristic spatial scale of synchrony, hereafter referred to as the decorrelation scale. For a given set of spatially referenced time series, Pearson's r correlation coefficient was computed for each possible location pair and plotted against the great circle distance (shortest distance across the spherical surface of Earth) separating that pair. By non-linear least squares estimation, the points were fit with an exponential decline,

$$
\mathrm{r}=a \mathrm{e}^{\left(\frac{-d}{\mathrm{v}}\right)}
$$

where $r$ is the correlation coefficient, $a$ is the correlation at 0 distance, $d$ is the distance between locations $(\mathrm{km})$, and $1 / v\left(\mathrm{~km}^{-1} ; \mathrm{v}>0\right)$ is the rate of synchrony decay. The characteristic spatial scale of synchrony based on such a model is customarily given as the e-folding scale or decorrelation scale of the exponential fit, the distance at which $r=e^{-1}$. Confidence intervals were derived from the 5th and 95th bootstrapped percentiles of the decorrelation scale $(\mathrm{n}=1000)$. We constrained our fits to perfect autocorrelation at 0 distance, $a=1$, to facilitate comparisons within our temporal analysis and with the results of Myers et al. (1995). With this constraint, the decorrelation scale of the model is given by $v(\mathrm{~km})$. Foregoing fitting an intercept ignores the noise in the data introduced by observation error and/or spatial heterogeneity. In theory, large observation errors relative to recruitment levels could skew the results of the recruitment analyses, but this was not the case for the recruitment datasets evaluated here. The exponential model assumes that the forcing agent generating synchrony is isotropic (Myers et al. 1995).

To confirm the appropriateness of bottom temperature as an environmental index, we calculated its spatial scale of synchrony for the time period 1970 to 1994, which coincides with the recruitment data analyzed by Myers et al. (1995). Each correlation was weighted by the lengths of its respective time series in the calculation of the decorrelation scale in order to correct for differences in the lengths of the time series.

To examine the temporal progression of synchrony, the physical and biological data were analyzed using a sliding window technique. For each 9 yr window, the decorrelation scale of synchrony was calculated from all datasets that were complete over that window. The scales then were plotted against the central years of the window. A 9 yr window was chosen because it yields 2 non-overlapping time periods with complete recruitment data for all 11 stocks, 1981 to 1989 and 1990 to 1998 . The first time period was one of relative strength for the Northwest Atlantic cod stocks, while the second spans the time of stock declines. Windows of 10 and $11 \mathrm{yr}$ yielded similar results.

The decorrelation plot has power because it considers the spatial correlation pattern across 55 data pairs. Individual pairwise correlations should be cautiously interpreted, however, because, given the $9 \mathrm{yr}$ window used, correlation coefficients must exceed \pm 0.67 to be considered significantly different from 0 with $95 \%$ confidence. Adjusting the degrees of freedom to account for autocorrelation in the data further increases the critical value. All calculations were carried out in the statistical software package $R$, version 2.6.0 (R Development Core Team 2007).

\section{RESULTS}

\section{Abiotic environment}

The decorrelation analysis of synchrony in bottom temperature anomalies for the time period corresponding to the datasets of Myers et al. (1995), 1970 to 1994, yielded a decorrelation scale equal to $431 \mathrm{~km}(5,95 \%$ 

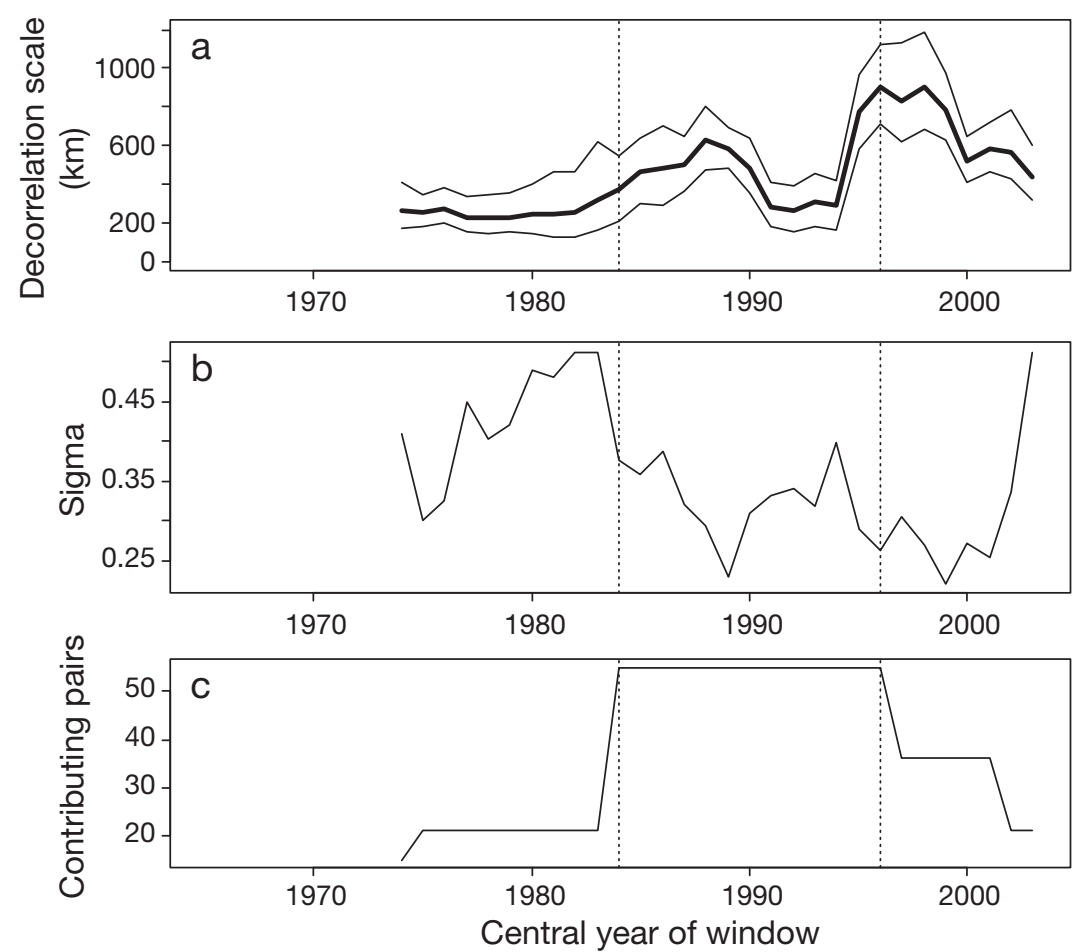

Fig. 5. A 9 yr sliding window analysis of bottom temperature anomaly synchrony. For each window, starting with 1970 to 1978 and sliding by 1 yr increments through to 1999 to 2007, the decorrelation analysis illustrated in Fig. 4 was carried out and the results plotted against the fifth year of the window (1974 through to 2003). (a) The decorrelation scale and 5, 95 bootstrapped percentile bounds. (b) Sigma, the square root of the variance of the residuals. (c) The number of stock pairs that contributed to each window (maximum of 55). Time series with less than the full $9 \mathrm{yr}$ of data were excluded. Dashed vertical lines mark the time period when a full complement of data was available from all 11 locations

ning the late 1980s and early 1990s, then rose again to $800 \mathrm{~km}$ for windows spanning the1990s. Re-examining the bottom temperature time series of Fig. 2, we see that the larger decorrelation scale in the 1990s reflects a tendency for bottom temperatures to trend upwards in all 7 northern areas (A to $\mathrm{G}$ ).

\section{Cod recruitment}

Cod recruitment declined in the majority of stocks examined, and was adequately described by the Lowess fits (Fig. 6). From the mid-1980s onwards, recruitment declined for the northern stocks (1-4), Gulf of St. Lawrence stocks $(5,6)$, and Western Scotian Shelf stock (9). Over the same time interval, the recruitment trend in the remaining stocks has either held steady (8) or decreased and then rebounded $(7,10$, and 11$)$. Removal of the trends revealed a consistent pattern of similar fluctuations among neighboring stocks in the high frequency residual recruitment time series (Fig. 7). For example, in 1976, recruitment dropped in every time series for Stocks 1 to 6, 8, and 9. Recruitment in Stocks 9 and 10 follow

bootstrapped confidence intervals: 344, $539 \mathrm{~km}$ ), with a square root variance of the residuals from the exponential decline, sigma, of 0.23 (Fig. 4). This closely matched the $460 \mathrm{~km}$ decorrelation scale reported by Myers et al. (1995) for Northwest Atlantic cod recruitment, lending further support to their interpretation, based on the time period when these stocks were relatively stable, that large-scale physical environmental factors forced recruitment synchrony. Low variance attests to the appropriateness of the model. The point scatter follows the pattern described by the exponential model: strong correlations between neighboring locations falling off to no relationship at larger separation distances. We conclude that bottom temperature anomalies are an appropriate environmental forcing factor for consideration in our analyses.

The sliding window analysis of bottom temperature synchrony revealed that the characteristic spatial scale of synchronous fluctuation has varied through time (Fig. 5). For the windows spanning the 1980s, the decorrelation scale varied between 400 and $600 \mathrm{~km}$. The scale decreased to roughly $300 \mathrm{~km}$ for windows span- similar trajectories throughout the length of their time series. Recruitment in Stocks 7 and 8 showed great similarity in the 1980s. Other episodes of coherent fluctuations at high frequencies are evident in the time series.

The sliding window analysis of recruitment synchrony for that portion of the time period for which recruitment data from at least 7 stocks contributed to the analyses (windows centered on 1975 to 1996), revealed that the decorrelation scale of recruitment synchrony also held relatively steady at approximately $500 \mathrm{~km}$ through the 1970s and 1980s (again, consistent with the results of the analysis by Myers et al. 1995), but declined to approximately $250 \mathrm{~km}$ in the windows spanning the 1990s (Fig. 8a). Over the same time interval, point scatter around the exponential fits showed the opposite trend: sigma increased from roughly 0.25 to 0.45 (Fig. 8b). This greater disparity between the actual correlations and the exponential model indicates that recruitment synchrony shifted from being a relatively universal, homogenous phenomenon to being a regionally-varying, localized phenomenon. 

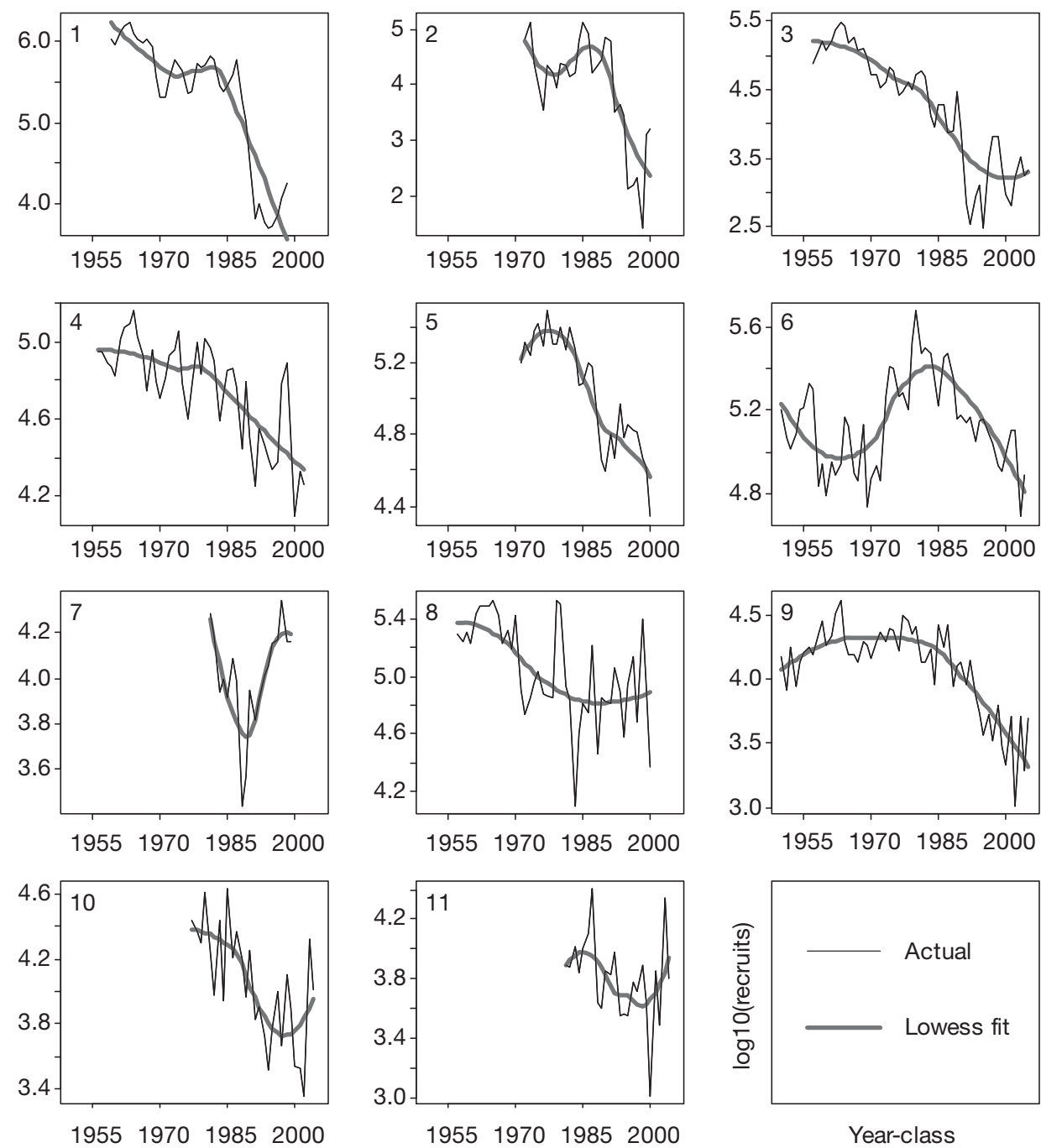

Fig. 6. Gadus morhua. Log-transformed recruitment versus birth year of each cohort. Lowess fits (10 yr span), plotted in red, trace the recruitment trends of the 11 stocks

These temporal differences are illustrated in the decorrelation plots of the 2 windows for which complete recruitment data for all 11 stocks were available: 1981 to 1989 , and 1990 to 1998 (Fig. 9a). During the interval 1981 to 1989 , a time of relative population strength and high recruitment for most of the 11 stocks (see Fig. 6), the decorrelation scale of synchrony was

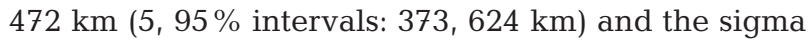
value was 0.31 . In contrast, during the interval 1990 to 1998, a time that spans major declines in stock abundance and recruitment, the decorrelation scale of synchrony was reduced to $214 \mathrm{~km}$ (5, $95 \%$ intervals: 92, $390 \mathrm{~km}$ ), and the sigma value increased to 0.42 . These declines are contrary to the expectation that decorrelation scales of physical and recruitment data should covary (Myers et al. 1995).
To illustrate where major changes in synchrony have occurred, the decorrelation plots are combined (Fig. 9b). Immediately evident are the losses of synchrony between most of the nearest neighboring stocks, those with spawning grounds separated by less than $500 \mathrm{~km}$. Both the environmental and dispersal synchrony forcing mechanisms predict that nearest neighbors should be the most strongly tied. Moreover, while many of the stock-pair relationships changed only moderately, correlations between some pairs were substantially strengthened and in others were erased over time. The relationships between some stock pairs shifted strongly negative in the later time period. Consistently, correlations with Stock 2, the most geographically isolated stock, remained negligible. 


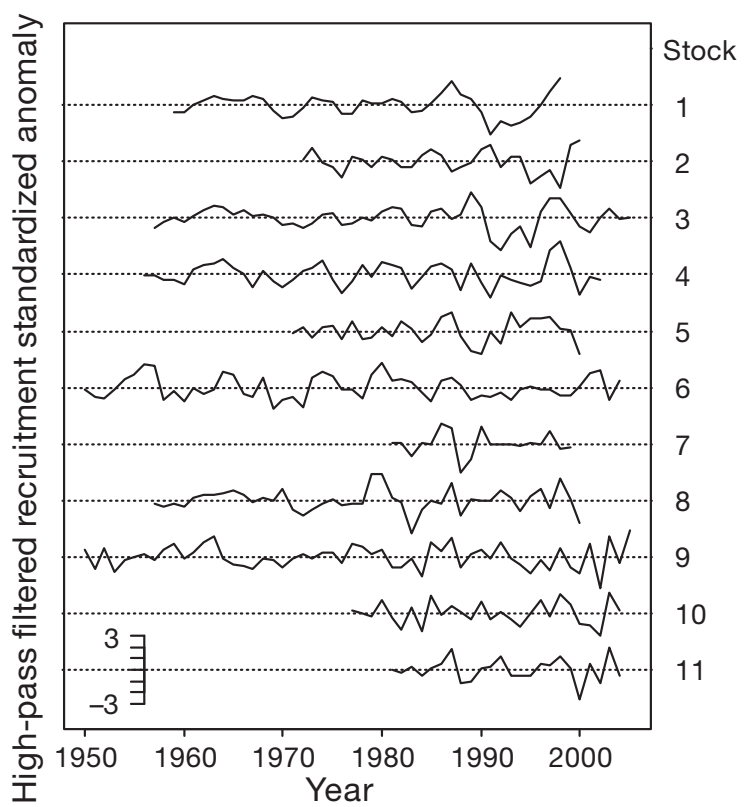

Fig. 7. Gadus morhua. Residuals from the Lowess trends (Fig. 6), illustrating the high frequency fluctuations in recruitment. The de-trended recruitment time series (the residuals) are plotted as standardized anomalies and centered at 0 in the 1990s. Contrary to the expectation following from Myers et al. (1995), a corresponding increase in the scale of cod recruitment synchrony did not occur. Rather, the decorrelation scale of cod recruitment synchrony, which had remained relatively stable at approximately 450 to $500 \mathrm{~km}$ during the 1970s and 1980s, declined to less than $300 \mathrm{~km}$ in the 1990s, where it remains.

In the 1990s, Northwest Atlantic cod stocks experienced severe abundance declines that, in conjunction with demographic changes, should have strengthened the influence of climate on recruitment. The severe abundance declines, which led to multiple stock collapses, were the result of years of overexploitation exacerbated by unfavorable environmental conditions (Myers \& Cadigan 1995, Shelton \& Lilly 2000, Choi et al. 2004, Shelton et al. 2006). The age structures of the remaining spawning stocks had also collapsed: over time, preferential fishing for the largest individuals disproportionately removed most of the older, more fecund animals from the populations (Law 2000). Cod recruitment is most strongly tied to climate, as indexed by the NAO, when spawning stock biomass is low (Brander, 2005; but see Stige et al. 2006). Ottersen et

\section{DISCUSSION}

The spatial pattern of synchrony in population abundances typically reflects the scale of one or more of the forcing agents that regulate population dynamics. For Northwest Atlantic cod stocks, a large body of previous work resulted in, and was consistent with, the hypothesis that variability in the physical environment, over scales of about $500 \mathrm{~km}$ and greater, influenced year class success, thereby inducing recruitment synchrony at a decorrelation scale of $460 \mathrm{~km}$ (Myers et al. 1995).

However, the addition of a temporal dimension to the analysis of recruitment synchrony in these cod stocks requires a reconsideration of this interpretation. In the absence of a temporal parameter, the decorrelation scale of bottom temperature $(430 \mathrm{~km})$ was consistent with the decorrelation scale of cod recruitment synchrony reported by Myers et al. (1995) (Fig. 4). However, when we reanalyzed the data using a sliding temporal window, we found that the temperature decorrelation scale had increased to approximately $800 \mathrm{~km}$
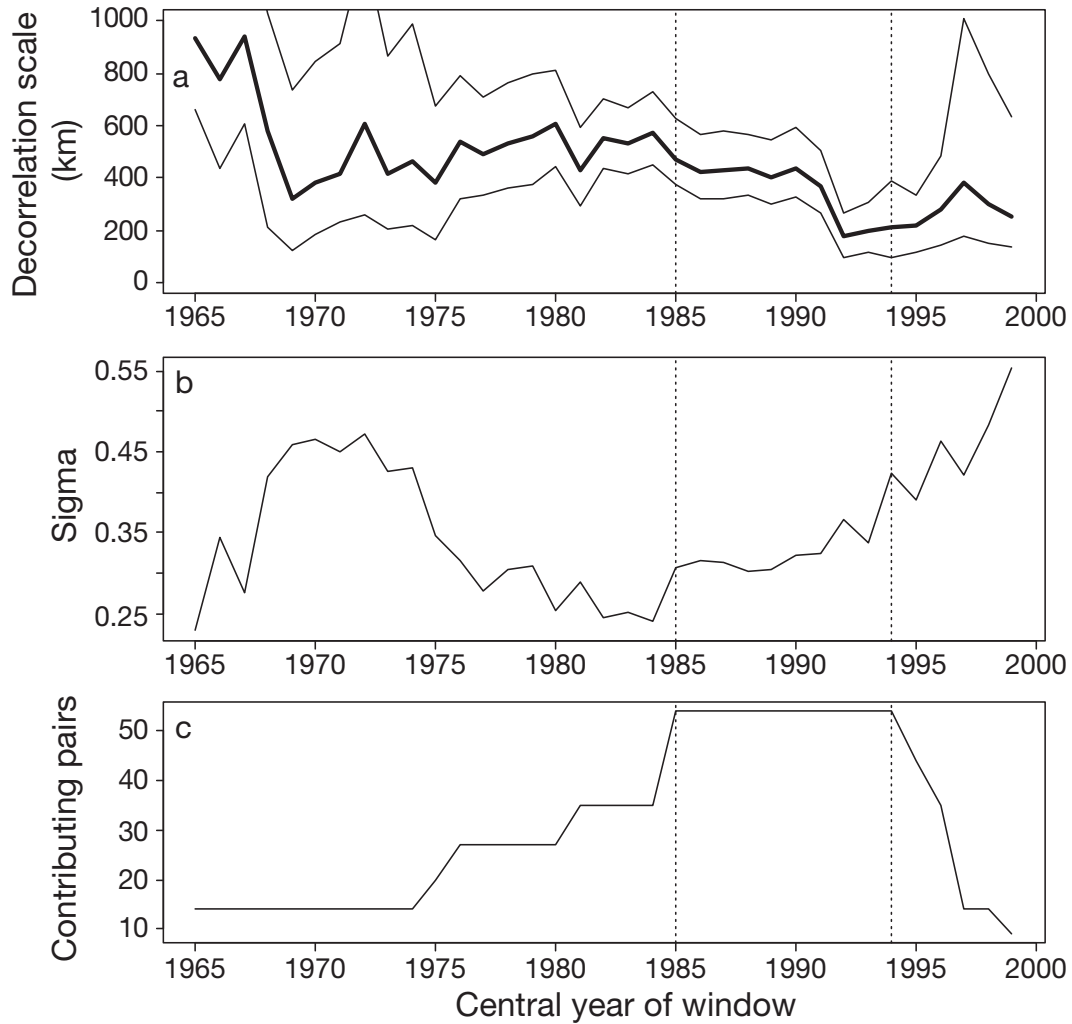

Fig. 8. Gadus morhua. Results of a 9 yr sliding window analysis of recruitment synchrony, plotted in the same manner as in Fig. 5. (a) Decorrelation scale, (b) sigma, (c) number of contributing data pairs. Dashed vertical lines mark the time period when a full complement of data was available from all 11 locations 


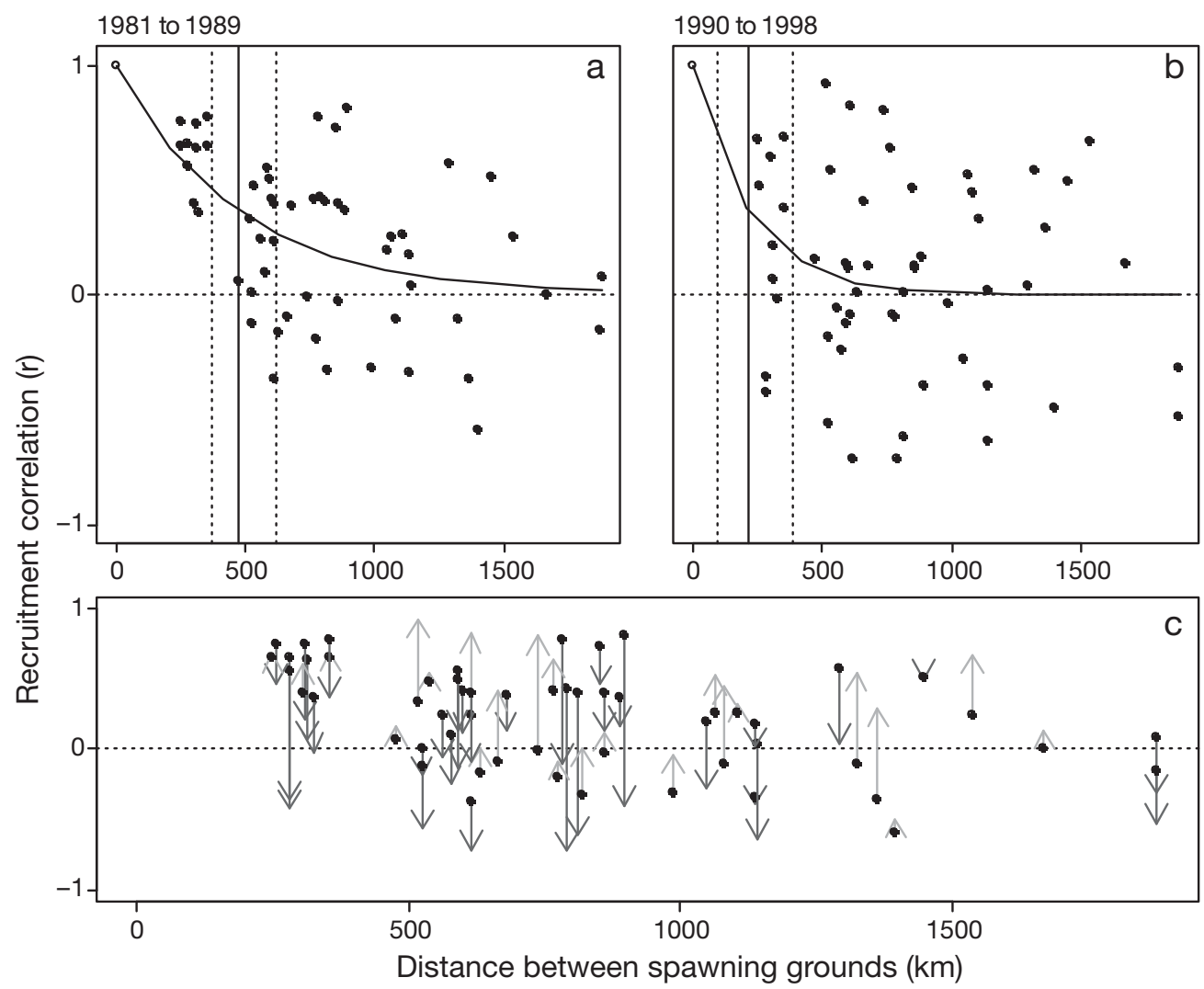

Fig. 9. Gadus morhua. Fits of the exponential model to the (a) 1981 to 1989 and (b) 1990 to 1998 recruitment data. In each plot, the solid and dashed vertical lines mark he decorrelation scale and its bootstrapped confidence intervals $(5,95 \%)$ respectively. The horizontal dashed line marks zero correlation for reference. (c) The change in correlation between the 2 time periods as a function of separation distance. The data are re-plotted as arrows from the 1981 to 1989 correlation to the 1990 to 1998 correlation, and shaded light and dark grey to indicate increases and decreases, respectively. The horizontal dashed line marks zero correlation for reference. Note the concentrated declines in correlations among nearest neighbors, i.e. those stocks separated by less than $500 \mathrm{~km}$

al. (2006) reported that the truncation of the age structure of Barents Sea cod stock strengthened the relationship of that stock's dynamics to climate.

In sharp contrast to expectations, and despite the continued influence of environmental forcing at large, and, for bottom temperature, increasing characteristic length scales, cod recruitment was characterized by a declining, localizing decorrelation scale during the 1990s. This inverse trend suggests that the link between stock dynamics and climate weakened and/or was superseded by other factors during this time interval.

However, the increased variance around the recruitment synchrony model during this same time interval is of note. The decorrelation analysis assumes that recruitment synchrony is homogenous and isotropic, and it yields a result that is generalized to all Northwest Atlantic cod stocks. The increase in variance about the exponential model reduced the validity of this assumption that synchrony is independent of the identities of the stock pairs. In fact, several of the stock pairs remained correlated at scales consistent with the hypothesis of the dominant role of large-scale environmental forcing (Fig. 9).

In our analyses, those nearest neighbor stocks that retained the highest levels of synchrony (high correlation coefficients) were most notably the most northern $(1,3,4)$ and most southern $(9,10,11)$ stock pairs (Fig. 9). Note that the southern stocks - Stocks 10 and 11 - underwent the least dramatic numerical and biomass reductions, so it is plausible that for these stocks, 'normal' dynamics were in play throughout the time series. The northern stocks suffered the greatest declines.

It is plausible that for the stocks near the northern range of the species, the impacts of stock life history changes were either insufficient to offset the influence of the environment, or in fact acted to amplify the link between recruitment and the environment. The species range hypothesis postulates that recruitment is more strongly influenced by environmental factors at the geographical limits of the species range (see 
Brunel \& Boucher 2006). Cod recruitment is most strongly related to water temperature at the cold, northern limits of the range, and this relationship becomes indiscernible in temperate waters (Planque \& Fredou 1999). Moreover, in cod, recruitment variability is higher at the geographic extremes of its range (Brunel \& Boucher 2006).

An alternative interpretation follows from the relative temporal changes in the decorrelation scales of cod recruitment and bottom temperature synchrony: historically, recruitment synchrony was induced by dispersal between populations operating in concert with large-scale environmental effects, and the localization of the scale of synchrony in the 1990s resulted from, in part, disruptions to dispersal patterns. There is considerable documentation of dispersal between the cod stocks studied. An analysis of decades of cod tagging data led Robichaud \& Rose (2004) to categorize $59 \%$ of the 101 Northwest Atlantic tagged cod groups studied as 'inaccurate homers' or 'dispersers.'

Stock abundance and recruitment estimation methods built on catch data skewed by cod dispersal behavior may generate unduly synchronous recruitment time series relative to actual recruitment levels. The age-structured population models used to generate the cod abundance time series we employed incorporate both research survey and landing data collected throughout the lifetime of a year class. Age-specific abundance estimates, including recruitment estimates, are back-calculated. If a disperser is captured in a management division distinct from its natal grounds, whether there on seasonal migration or as an immigrant, that catch record is incorporated into the productivity estimates for the capture division. Capture division recruitment estimates are inflated, and the natal division recruitment estimates are depressed. Thus, in those instances where dispersers moved from an abundant (productive) stock to a less abundant (productive) one, the abundance estimates for the 2 stocks would exhibit synchrony.

The age-specific dispersal of young Icelandic cod exemplifies the misleading influence that catch records skewed by dispersal can have on assessment population estimates. Substantial temporary dispersal of young Icelandic cod to West Greenland cod populations in years of strong recruitment, followed by a return to natal spawning areas at maturity, greatly biases abundance estimates for both stocks, and is accounted for in the analyses of stock dynamics (Frank 1992).

Stock mixing at times other than spawning may result in simultaneous, differentially harmful exploitation of multiple stocks. For example, cod tagged in the northern Gulf of St. Lawrence (Stock 5) have been recaptured off southern Newfoundland (Stock 4) and off Labrador (Stock 1). These occurrences have caused concern that efforts to rebuild Stock 5 are being hampered by too many fish from this stock being intercepted while mixing with Stock 4, which now shows signs of a robust recovery and thus has a high fishing quota (Yvelin et al. 2005). This pitfall of unintended exploitation of threatened populations that have intermixed with healthy ones is repeatedly encountered in other fisheries (northwest Pacific salmon, Policansky \& Magnuson 1998; Atlantic blue fin tuna, Block et al. 2005).

The dramatic declines in cod abundance of the 1990s had the potential to dramatically influence dispersal rates. First, at low abundances, fewer propagules are available. If dispersal is density-dependent, lower abundances would also have dramatically reduced the density pressure to disperse, thereby further limiting the number of dispersers. The cod stocks of the Scotian shelf display significant area-abundance relationships (Fig. 10). The resulting geographic isolation of reduced abundances may further hinder dispersal, leaving populations fragmented.

Local population dynamics modulated by immigrants from neighboring populations are a feature of metapopulations (defined as a collection of primarily reproductively insular local populations that undergo a limited exchange of individuals; Kritzer \& Sale 2004). Whereas traditional metapopulations are structured by habitat, an Atlantic cod metapopulation would consist of the discrete substock spawning groups that characterize the cod stocks of the Northwest Atlantic (Smedbol \& Wroblewski 2002), and are defined by meristic (Templeman 1962), genetic (Ruzzante et al. 1999, Pogson et al. 2001, Wirgin et al. 2007), and behavioral (Robichaud \& Rose 2004) data. Metapopulation structure has been explicitly proposed for the northern cod stocks on the Newfoundland/Labrador shelf (Smedbol \& Wroblewski 2002), and for the North Sea and west Scotland cod in the northeast Atlantic (Wright et al. 2006). The 10 spawning subcomponents of the North Sea and west Scotland cod stocks show regional variability at the substock level, consistent with the dynamics of a metapopulation (Holmes et al. 2008).

A key characteristic of metapopulation biology is that the connectivity between local populations in part shapes the dynamics of local spawning subcomponents and promotes species persistence at the metapopulation level. If the shift of the spatial scale of synchrony from large to local scale that occurred in the Northwest Atlantic cod in the 1990s indicates that connectivity has fractured, the consequences must be considered. Firstly, immigrants to a population suffering local stochastic failure can 'rescue' that population from decline (Brown \& Kodric-Brown 1977). Decreased 


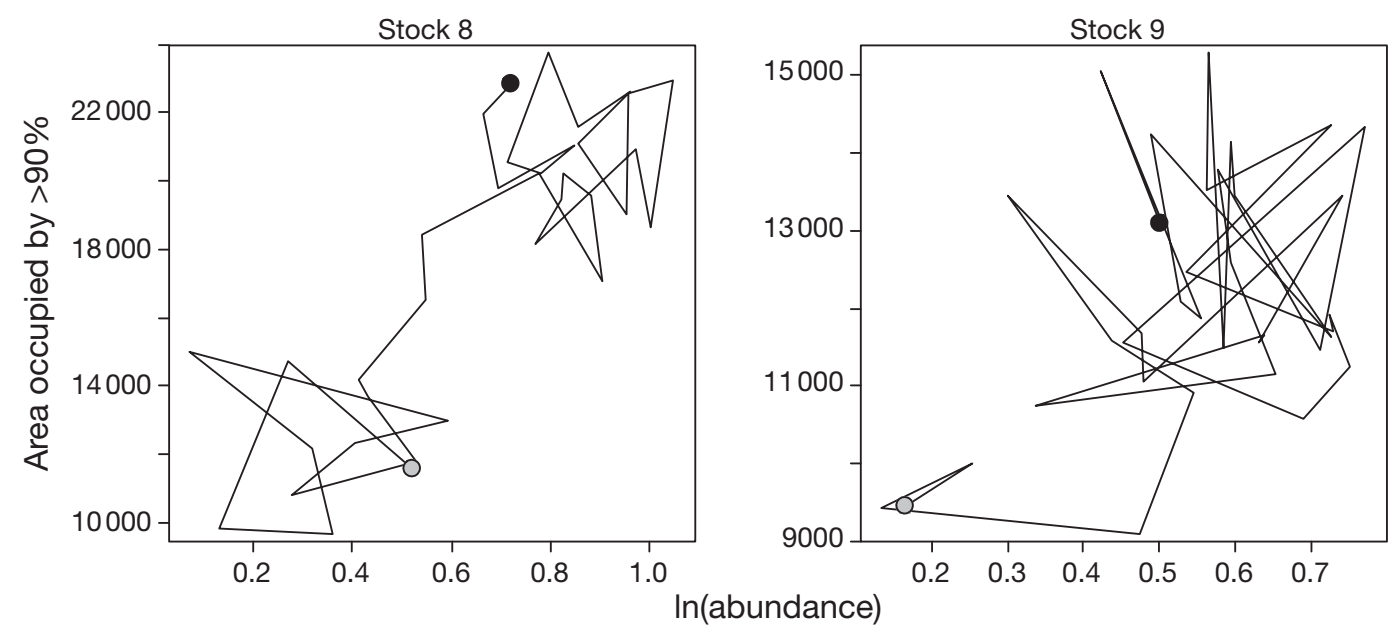

Fig. 10. Gadus morhua. Up-to-date area-abundance relationships for the Scotian shelf cod stocks, evaluated in the manner of Fisher \& Frank (2004). The 1970 and 2006 values are plotted as black and grey dots, respectively. Annual abundances are plotted against the areas $\left(\mathrm{km}^{2}\right)$ containing $>90 \%$ of cod caught in the annual research vessel groundfish survey samples. Pearson's correlation coefficient between area and $\ln$ (abundance) is 0.81 for Stock 8 ( $p<0.0001)$ and 0.35 for Stock 9 ( $p<0.05)$

connectivity would dampen the effectiveness of this buffer. Second, persistent input from an overproductive local 'source' population can enable the persistence of an otherwise unsustainable, underproductive 'sink' population (Pulliam 1988). If the source population ceases to provide dispersers, the sink population settles into a lower but sustainable abundance level and/or becomes susceptible to collapse or extinction.

Could a reduction in or loss of these dispersal dynamics at low stock and sub-stock abundances be partly responsible for the lack of cod recovery? Recovery predictions for collapsed stocks are typically based on a stock-recruitment relationship compiled at the stock level, which assumes the existence of a single fish population that must grow to recover. However, in reality it is often necessary for multiple subcomponents to rebuild to achieve recovery (Frank \& Brickman 2000). Local populations characterized by depensatory dynamics and therefore bound towards, or at, local extinction would act to delay, if not prevent, recovery of the aggregate stock.

If cod do function as a metapopulation, could dispersal be the future avenue for recovery in the Northwest Atlantic? With a search for potential source-sink neighboring populations in mind, we examined the productivities of the 11 cod stocks we studied. In Fig. 11, the cod stock recruitment rates, expressed as log R/SSB, are plotted against SSB and traced through time. The time period of stock abundance declines and the years that follow, taken as 1990 onwards, is highlighted to show if, and how, productivity has shifted. We fit a simple regression to each time period for each stock.
Based on the results, we hypothesize that the strongest candidate rescue populations are the stocks from the center of the species range that are characterized by compensatory dynamics (4 to 8). In theory, compensatory dynamics (higher productivity at low biomass) increase the growth rate of a depleted population, promoting recovery (Jennings et al. 2001). The northernmost stocks (1 to 3), which were historically characterized by steady or negative (compensatory) productivity-biomass relationships, now show depressed productivity levels relative to the historical norm (Fig. 11) and have bleak prospects for recovery. Genetic evidence suggests that, in the past, populations in Stocks 1 and 3 have rebuilt from low biomass by local resurgence (Ruzzante et al. 2001). Given the contemporary lack of recovery, perhaps due to a shift to depensatory dynamics, local resurgence may no longer be possible. The future of these stocks, if one exists, may ultimately depend on the re-colonization of local populations that are currently commercially extinct through immigration from adjacent stocks. Rescue by an influx of migrants seems less likely for Stock 2 (Flemish Cap), isolated as it is by distance and ocean currents. This stock is the natural exemplar of an isolated population that lacks the buffer of the rescue effect.

The obvious candidate 'rescue stocks' from which the collapsed northernmost cod populations might receive substantial numbers of immigrants are Stocks 4 and 5 (southern Newfoundland and the northern Gulf of St. Lawrence). These populations are both characterized by strong compensatory dynamics (Fig. 11). Productivity levels in Stock 4 appear to have 

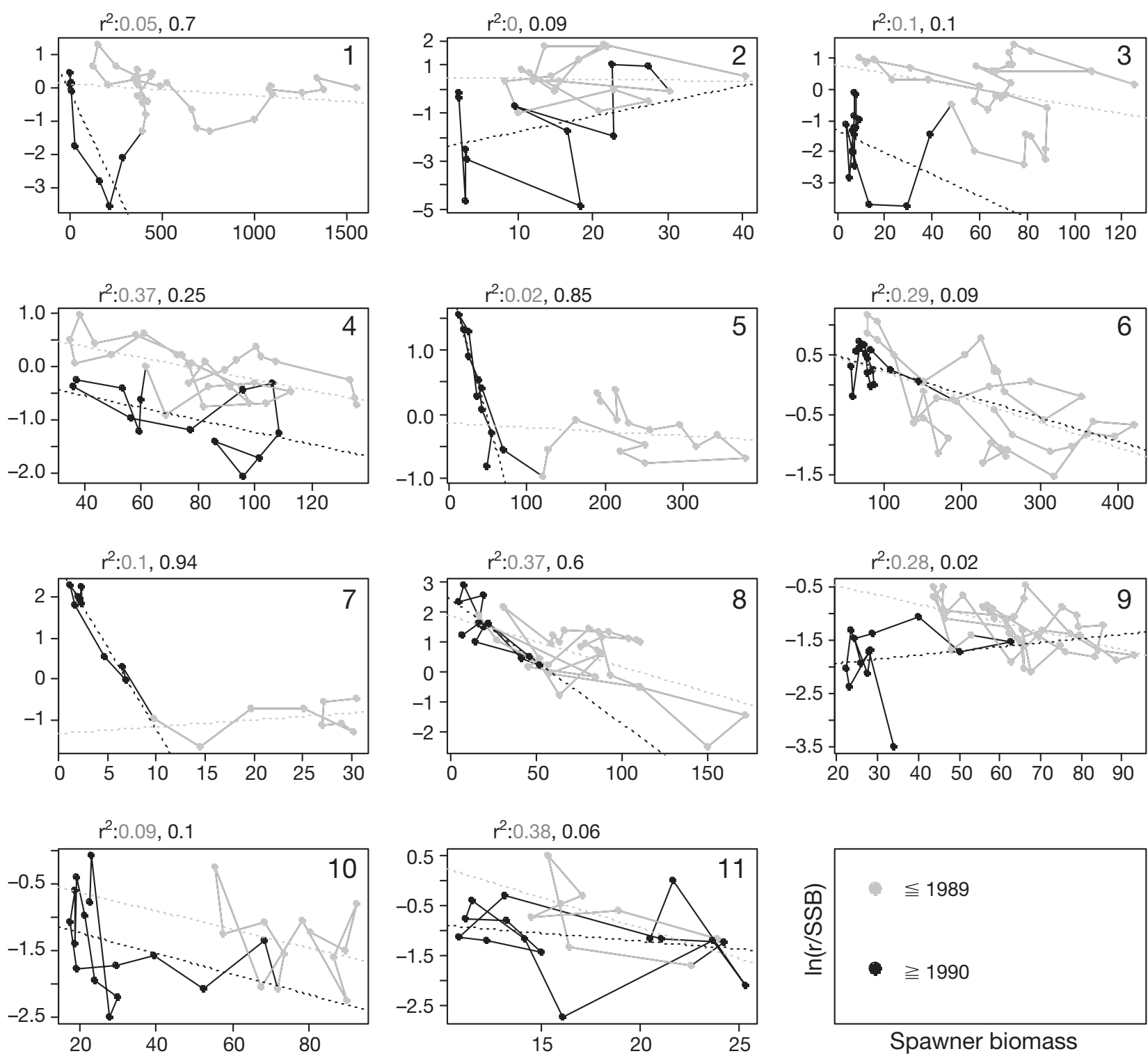

Fig. 11. Gadus morhua. Log-transformed recruitment rate versus spawning stock biomass (SSB) for each stock (1 to 11). The data series are split into year-classes before (grey) and after (black) 1989, and the data points are connected in chronological order. Dashed grey and black lines give the linear fits of the data points (the Ricker stock recruitment model) for the 2 time periods, respectively. Panel titles give the $\mathrm{r}^{2}$ values of the linear fits of the 2 data sets, before 1989 in grey, and from 1990 to 2005 in black. Some stocks appear to have different compensatory dynamics between the 2 time periods, while others appear stable in time

reset to a lower baseline following the collapse, but Stock 4 has rebounded strongly. Given the aforementioned frequency at which fishes tagged in the northern Gulf of St. Lawrence are captured off southern Newfoundland (Yvelin et al. 2005), perhaps rebuilding of stock via dispersal from Stock 5 is underway. By the metric of temporally persistent compensatory dynamics, Stocks 6, 7, and 8 (the southern Gulf of St. Lawrence, Sydney Bight, and eastern Scotian Shelf) are also potential future sources of migrants. However, all currently remain at low abundance.
Otolith studies confirm predictions based on tagging studies that cod from Stocks 4 and 5 mix while overwintering, as do cod from Stocks 6 to 8, though there is very limited mixing between the 2 groups across the Laurentian Channel in the Gulf of St. Lawrence (Campana et al. 1999). The Gulf of St. Lawrence stocks $(5,6)$ experienced high adult natural mortality rates from the late 1980s through 2001 in the north and continuing to the present in the south. The high mortality is hypothesized to be due to high seal predation (Chouinard et al. 2005, DFO 2007), but high emigration would also be 
reflected as high adult mortality in the population estimations.

Tagging studies indicate the 3 southernmost stocks, the western Scotian Shelf and Bay of Fundy stock (9), Georges Bank stock (10), and Gulf of Maine stock (11), have high levels of individual exchange, including cross-channel movements and seasonal migration patterns (Hunt et al. 1999). Migrants from Stocks 10 and 11 may be critical to the rebuilding of Stock 9, where recent productivity is depressed and in discord with the historical compensatory dynamics (Fig. 11). Migrants from Stock 8 are unlikely to exert a significant influence on the rebuilding of Stock 9. Tagging data from 1979 to 1997 indicated that fewer than $3 \%$ of cod tagged east of the Stock 9 NAFO geographic boundary dispersed towards Stocks 9 to 11. Movement from south to north was more substantial; about $25 \%$ of cod captured in the area east of the Stock 9 NAFO area designation were tagged in one of the southern locations. As the southern stocks rebuild, particularly Stock 9, the abundance increase may disperse northward, cascading upstream.

Our analysis of cod recruitment synchrony in the 1990s suggests that the local level is of fundamental importance to the dynamics of cod populations. Now, when local stock dynamics have been sufficiently altered and interrupted, the effect of these changes appears to supersede the influence of large-scale environmental conditions, widely believed to have forced cod synchrony in the decades prior to the stock depletions/collapses (Templeman 1972, Garrod \& Colebrook 1978, Koslow 1984, Koslow et al. 1987, Thompson \& Page 1989, Myers et al. 1995). We hypothesize that, while still not adequately quantified (or even formerly considered), dispersal between populations contributed significantly to the synchrony in stock abundances (recruitment) observed in the past. The substock structure and tagging data for the Northwest Atlantic cod stocks indicate that dispersal commonly characterized these populations, suggesting cod metapopulation structure. Modeling studies could be used to initially address questions that follow from this hypothesis. Are known dispersal rates compatible with (1) the levels of dispersal necessary to alter local population dynamics and (2) the connectivity threshold(s) above which substock genetic distinctiveness would degrade?

The observed connectivity between cod stocks, and the current dominance of local over large-scale governing dynamics, implies that Northwest Atlanticwide cod stock rebuilding schemes should benefit from allowing potential source populations to grow and overproduce, thereby increasing the abundance of potential emigrants. However, isolated divisional stock management is well established. Switching to a connectivity management framework would be a substantial undertaking, both in design and implementation.

Acknowledgements. Funding for this research was provided by NSERC Discovery Grants to K.T.F. and W.C.L. and by an award from the Dalhousie Department of Graduate Studies to J.E.K. B. Petrie, G. Chouinard, and E. Colbourne provided bottom temperature data. We thank C. Taggart and K. Thompson for their helpful suggestions and manuscript reviews, and N. Shackell and J. Fisher for their critiques of earlier drafts of the manuscript. L. Petrie assisted with some of the graphics.

\section{LITERATURE CITED}

Bjørnstad ON, Ims RA, Lambin X (1999) Spatial population dynamics: analyzing patterns and processes of population synchrony. Trends Ecol Evol 14:427-432

Block BA, Teo SLH, Walli A, Boustany A and others (2005) Electronic tagging and population structure of Atlantic blue fin tuna. Nature 434:1121-1127

> Brander KM (1995) The effect of temperature on growth of Atlantic cod (Gadus morhua). ICES J Mar Sci 52:1-10

Brander KM (2000) Effects of environmental variability on growth and recruitment in cod (Gadus morhua) using a comparative approach. Oceanol Acta 23:485-496

$>$ Brander KM (2005) Cod recruitment is strongly affected by climate when biomass is low. ICES J Mar Sci 62:339-343

Brown JH, Kodric-Brown A (1977) Turnover rates in insular biogeography: effect of immigration on extinction. Ecology 58:445-449

Brunel T, Boucher J (2006) Pattern of recruitment variability in the geographical range of the exploited northeast Atlantic fish species. J Sea Res 55:156-168

Campana SE, Chouinard GA, Hanson JM, Frechet A (1999) Mixing and migration of overwintering Atlantic cod (Gadus morhua) stocks near the mouth of the Gulf of St. Lawrence. Can J Fish Aquat Sci 56:1873-1881

Choi JS, Frank KT, Leggett WC, Drinkwater K (2004) Transition to an alternate state in a continental shelf ecosystem. Can J Fish Aquat Sci 61:505-510

Chouinard GA, Swain DP, Hammill MO, Poirier GA (2005) Covariation between grey seal (Halichoerus grypus) abundance and natural mortality of cod (Gadus morhua) in the southern Gulf of St. Lawrence. Can J Fish Aquat Sci 62:1991-2000

Colbourne E, Craig J, Fitzpatrick C, Senciall D, Stead P, Bailey W (2006) An assessment of the physical oceanographic environment on the Newfoundland and Labrador Shelf during 2005. CSAS Res Doc 2006/030

DFO (Department of Fisheries and Oceans, Canada) (2007) Accounting for changes in natural mortality in Gulf of St. Lawrence cod stocks. DFO CSAS Sci Advis Rep 2007/002

Field JC, Ralston S (2005) Spatial variability in rockfish (Sebastes spp.) recruitment events in the California Current System. Can J Fish Aquat Sci 62:2199-2210

Fisher JAD, Frank KT (2004) Abundance-distribution relationships and conservation of exploited marine fishes. Mar Ecol Prog Ser 279:201-213

Frank KT (1992) Demographic consequences of age-specific dispersal in marine fish populations. Can J Fish Aquat Sci 49:2222-2231 
Frank KT, Brickman D (2000) Allee effects and compensatory population dynamics within a stock complex. Can J Fish Aquat Sci 57:513-517

Garrod DJ, Colebrook JM (1978) Biological effects of variability in the North Atlantic Ocean. Rapp P V Réun Cons Int Explor Mer 173:128-144

Hanski IA, Gilpin ME (eds) (1997) Metapopulation biology: ecology, genetics, and evolution. Academic Press, London

Holmes SJ, Wright PJ, Fryer RJ (2008) Evidence from survey data for regional variability in cod dynamics in the North Sea and West of Scotland. ICES J Mar Sci 65:206-215

Hunt JJ, Stoba WT, Almeida F (1999) Movement of Atlantic cod, Gadus morhua, tagged in the Gulf of Maine area. Fish Bull 97:842-860

Jennings S, Kaiser MA, Reynolds JD (2001) Marine fisheries ecology. Blackwell Publishing, Oxford

Koslow JA (1984) Recruitment patterns in Northwest Atlantic fish stocks. Can J Fish Aquat Sci 41:1722-1729

Koslow JA, Thompson KR, Silvert W (1987) Recruitment to Northwest Atlantic cod (Gadus morhua) and haddock (Melanogrammus aeglefinus) stocks: influence of stock size and climate. Can J Fish Aquat Sci 44:26-39

Kritzer JP, Sale PF (2004) Metapopulation ecology in the sea: from Levins' model to marine ecology and fisheries science. Fish Fish 5:131-140

Law R (2000) Fishing, selection, and phenotypic evolution. ICES J Mar Sci 57:659-668

Leggett WC, Frank KT (2008) Paradigms in fisheries oceanography. Oceanogr Mar Biol Annu Rev 46:331-364

Liebhold A, Koenig WD, Bjornstad ON (2004) Spatial synchrony in population dynamics. Annu Rev Ecol Evol Syst 35:467-490

Link JS, Brodziak JKT (2002) Status of the northeast US continental shelf ecosystem. US Dept Commerce, NFSC Ref Doc $02-11$

Manderson JP (2006) The spatial scale of phase synchrony in winter flounder (Pseudopleuronectes americanus) production increased among southern New England nurseries in the 1990s. Can J Fish Aquat Sci 65:340-351

Marteinsdottir G, Ruzzante D, Nielsen EE (2005) History of the North Atlantic cod stocks. ICES CM 2005/AA:19

Mayo RK, Col LA (2006) The 2005 assessment of the Gulf of Maine Atlantic cod stock. US Dept Commerce, NEFSC Ref Doc 06-02

Morgan MJ, Murphy EF, Brattey F (2007) An assessment of the cod stock in NAFO Divisions 3NO. NAFO SCR Doc $07 / 40$

> Mueter FJ, Petermann RM, Pyper BJ (2002) Opposite effects of ocean temperature on survival rates of 120 stock of Pacific salmon (Oncorhynchus spp.) in the northern and southern areas. Can J Fish Aquat Sci 59:456-463

Myers RA (1998) When do environment-recruitment correlations work? Rev Fish Biol 8:285-305

Myers RA, Barrowman NJ (1996) Is fish recruitment related to spawner abundance? Fish Bull 94:707-724

Myers RA, Cadigan NG (1995) Was an increase in natural mortality responsible for the collapse of northern cod? Can J Fish Aquat Sci 52:1274-1285

> Myers RA, Mertz G, Barrowman NJ (1995) Spatial scales of variability in cod recruitment in the North Atlantic. Can J Fish Aquat Sci 52:1849-1862

> Myers RA, Mertz G, Bridson J (1997) Spatial scales of interannual recruitment variations of marine, anadromous, and freshwater fish. Can J Fish Aquat Sci 54:1400-1407

O'Brien L, Shepherd N, Col LA (2006) Assessment of the Georges Bank Atlantic cod stock for 2005. US Dept Commerce, NEFSC Ref Doc 06-10
Ottersen G, Hjermann DØ, Stenseth NC (2006) Changes in spawning stock structure strengthen the link between climate and recruitment in a heavily fished cod (Gadus morhua) stock. Fish Oceanogr 15:230-243

Peterman RM, Pyper BJ, Lapointe MF, Adkinson MD, Walters CJ (1998) Patterns of covariation in survival rates of British Columbian and Alaskan sockeye salmon stocks. Can J Fish Aquat Sci 55:2503-2517

Petrie B, Pettipas RG, Petrie WM, Soukhovtsev VV (2006) Physical oceanographic conditions on the Scotian Shelf and in the Gulf of Maine during 2005. CSAS Res Doc 2006/040

Planque B, Fredou T (1999) Temperature and the recruitment of Atlantic cod (Gadus morhua). Can J Fish Aquat Sci 56:2069-2077

> Pogson GH, Taggart CT, Mesa KA, Boutilier RG (2001) Isolation by distance in the Atlantic cod, Gadus morhua, at large and small geographic scales. Evolution 55:131-146

Policansky D, Magnuson JJ (1998) Genetics, metapopulations, and ecosystem management of fisheries. Ecol Appl 8:S119-S123

> Pulliam HR (1988) Sources, sinks, and population regulation. Am Nat 132:652-661

Pyper BJ, Mueter FJ, Peterman RM, Blackbourn DJ, Wood CC (2001) Spatial covariation in survival rates of Northeast Pacific pink salmon (Oncorhynchus gorbuscha). Can J Fish Aquat Sci 58:1501-1515

R Development Core Team (2007). R: A language and environment for statistical computing. R Foundation for Statistical Computing, Vienna, Austria. Available at: http://www.R-project.org

Robichaud D, Rose GA (2004) Migratory behaviour and range in Atlantic cod: inference from a century of tagging. Fish Fish 5:185-214

Ruzzante DE, Taggart CT, Cook D (1999) A review of the evidence for genetic structure of cod (Gadus morhua) populations in the NW Atlantic and population affinities of larval cod off Newfoundland and the Gulf of St. Lawrence. Fish Res 43:79-97

Ruzzante DE, Taggart CT, Doyle RW, Cook D (2001) Stability in the historical pattern of genetic structure of Newfoundland cod (Gadus morhua) despite the catastrophic decline in population size from 1964 to 1994. Conserv Genet 2:257-269

Shelton PA, Lilly GR (2000) Interpreting the collapse of the northern cod from survey and catch data. Can J Fish Aquat Sci 57:2230-2239

Shelton PA, Sinclair AF, Chouinard GA, Mohn R, Duplisea DE (2006) Fishing under low productivity conditions is further delaying recovery of Northwest Atlantic cod (Gadus morhua). Can J Fish Aquat Sci 63:235-238

Smedbol RK, Wroblewski JS (2002) Metapopulation theory and northern cod population structure: interdependency of subpopulations in recovery of a groundfish population. Fish Res 55:161-174

Stige LC, Ottersen G, Brander K, Chan KC, Stenseth NC (2006) Cod and climate: effect of the North Atlantic Oscillation on recruitment in the North Atlantic. Mar Ecol Prog Ser 325:227-241

Swain DP, Frank KT (2000) Depth-dependent vertebral number of Atlantic cod (Gadus morhua) on the Magdalen Shallows and Scotian Shelf: stock mixing or microgeographic trends within populations? Can J Fish Aquat Sci 57: 2393-2401

Swain DP, Currie LG, Chouinard GA, Poirier GA, Savoie L, Hurlbut T, Daigle D (2007a) Assessment of the southern Gulf of St. Lawrence cod stock, March 2007. CSAS Res Doc 2007/033 
Swain DP, Sinclair AF, Hanson JM (2007b) Evolutionary response to size-selective mortality in an exploited fish population. Proc R Soc Lond B Biol Sci 274:1015-1022

Templeman W (1962) Divisions of cod stocks in the Northwest Atlantic. Int Comm NW Atl Fish. Redbook (Part III):79-123

Templeman W (1972) Year-class success in some North Atlantic stocks of cod and haddock. Int Comm NW Atl Fish, Spec Publ 8

> Thompson KR, Page FH (1989) Detecting synchrony of recruitment using short, autocorrelated time series. Can J Fish Aquat Sci 46:1831-1838

Editorial responsibility: Cynthia Jones,

Norfolk, Virginia, USA
Wirgin IA, Kovach I, Maceda L, Roy NK, Waldman J (2007) Stock identification of Atlantic cod in U.S. waters using microsatellite and single nucleotide polymorphism DNA analyses. Trans Am Fish Soc 136:375-391

Wright PJ, Neat FC, Gibb FM, Gibb IM, Thordarson H (2006) Evidence for metapopulation structuring in cod from the west of Scotland and North Sea. J Fish Biol 69: 181-199

Yvelin JF, Frechet A, Brethes JC (2005) Migratory routes and stock structure of cod from the northern Gulf of St. Lawrence (3Pn, 4RS). CSAS Res Doc 2005/055

Submitted: October 21, 2008; Accepted: July 23, 2009

Proofs received from author(s): October 20, 2009 